\title{
Investigation of immunoglobulin (IgE, IgA, IgG, IgM) concentrations in calves
} naturally infected with coccidiosis

Research Article

Volume: 4, Issue: 1 April 2020

Pages: $1-7$

\section{Article History}

Received: 02.03.2020 Accepted: 01.04.2020 Available online: 02.04 .2020

\section{Nazan Eğlenti ${ }^{1}$, Süleyman Kozat ${ }^{* 1}$, Vural Denizhan ${ }^{2}$}

1. Van Yuzuncu Yil University, Faculty of Veterinary Medicine, Department of Internal Medicine, Zeve Campus, 65080 Van-Turkey. 2. Van Yuzuncu Yil University, Faculty of Veterinary Medicine, Department of Parasitology, Zeve Campus, 65080 Van-Turkey.

Eğlenti, N.: ORCID: 0000-0001-5795-4188; Kozat, Z.: ORCID: 0000-0001-5089-2623, Denizhan, V. : ORCID: 00000002-0531-9550

\begin{abstract}
The aim of this study was to determine immunoglobulin (IgA), immunoglobulin (IgE), immunoglobulin (IgG) and immunoglobulin (IgM) levels of calves naturally infected with coccidiosis and to determine the relationship between infection and calf immunity. The material of this study consisted of 30 calves (21-44 days old) which were brought to clinics of Van Yuzuncu Yil University, Faculty of Veterinary Medicine, of which 20 calves that were diagnosed as coccidiosis by detecting Eimeria spp. oocysts according to native faecal examination and 10 healthy calves as control group. For hematological and biochemical analysis, blood samples were taken from all animals from the v. jugularis before treatment. According to statistical analyses; there was a statistically significant increase in hematological parameters such as white blood cell count (WBC), hematocrit value (Hct), mean corpuscular volume (MCV), monocyte count (Mon) $(P<0.05)$ and neutrophil (Neu) percentage $(p<0.01)$, whereas there was a statistical decrease in lymphocyte (Lym) percentage and mean corpuscular hemoglobin concentration $(\mathrm{MCHC}) \quad(\mathrm{P}<0.05)$ levels. Besides, there was a significant increase in urea and creatinine $(P<0.05)$ levels of calves with coccidiosis compared to control group. IgA, IgE, IgG and IgM concentrations of calves with coccidiosis were significantly lower than the control group $(P<0.001)$. As a result; there was a relationship between calf immunity and the risk of infection of calves with coccidiosis. It was concluded that determining passive transfer failure levels and oral immunoglobulin supplementation to calves with passive transfer failure would reduce the risk of coccidiosis in newborn calves.
\end{abstract}

Keywords: calf, coccidiosis, immunoglobulin.

DOI: 10.30704/http-www-jivs-net.691671

To cite this article: Eğlenti, N., Kozat, S., Denizhan, V. (2020). Investigation of immunoglobulin (IgE, IgA, IgG, IgM) concentrations in calves naturally infected with coccidiosis. Journal of Istanbul Veterinary Sciences. 4(1), 1-7, Abbreviated Title: J Ist Vet Sci

\section{Introduction}

Coccidiosis is an important disease affecting poultry, cattle, sheep, goats (Aydin and Aslan, 2012; Ocal, 2016), pigs and rabbits (Baydar and Ozubek, 2012; Sultana et al., 2014). In addition, although coccidiosis is less commonly diagnosed in dogs, cats and horses, the disease can also be observed in these animals clinically. It is especially severe in calves (Mundt et al., 2005; Baydar and Ozubek, 2012). Coccidiosis is an infectious,

*Corresponding Author: Süleyman Kozat

E-mail: skozat@hotmail.com acute or chronic protozoan disease characterized by enteritis (Aydın and Aslan, 2012), causing poor economic losses, susceptibility to other diseases and death, especially in breeding livestock and calf breeding (Mundt et al., 2005; Cicek et al., 2007; Baydar and Ozubek, 2012). The disease causes anemia, weakness, developmental retardation and decreased productivity in animals (Mundt et al., 2005; Cicek et al., 2007; 
Baydar and Ozubek, 2012). Although coccidiosis infection occurs in all seasons of the year, it occurs mostly in winter and early spring and causes severe disease especially in young calves up to 6 months (Bangoura et al., 2007; Baydar and Ozubek, 2012). As a result of studies carried out in the world, 17 Eimeria and 2 Isospora species have been reported to be the cause of cattle coccidiosis (Cicek et al., 2007; Baydar and Ozubek 2012; Bozdag, 2018). Eimeria bovis (E. bovis) and Eimeria zuernii (E. zuernii) are the most pathogenic species in cattle (Cicek et al., 2007; Baydar and Ozubek, 2012). In Turkey, 11 Eimeria and 1 Isospora species have been reported to cause bovine coccidiosis. Pathologically, the destruction of intestinal epithelial cells leads to the formation of villi loss, impaired absorption, enteritis, dehydration and diarrhea (Arslan et al., 2015). Various factors such as secondary diseases that cause weakening of the immune system of animals at the outbreak of the disease, weaning, excessive watery feeds such as feed change, transport, shearing, silage, maintenance, feeding, air exchange, crowded stables and lack of stable hygiene play an important role (Aydin and Aslan, 2012). As with most parasitic diseases, coccidiosis also changes many of the biochemical and hematological parameters (Arslan et al., 2015). Immunoglobulins are molecules in the immune system that have antigen-binding site and can combine with antigens that cause them to form. Thanks to these properties, they cause reactions in the body (YIlmaz and Akgul, 2014).

The main purpose of immunoglobulins; it is to be inactive by binding to the antigen and then forming the antigen-antibody compound, making it easier for the antigen to gather together and to be removed by phagocytosis (Senturk and Esen, 2012).

In this study; it was aimed to determine the immunoglobulin levels in coccidiosis disease. It is foreseen to reveal the importance of immunoglobulins in calf coccidiosis infection, which is common in veterinary medicine and causes significant economic losses.

\section{Material and methods}

The material of this study diarrhea brought to Van Yuzuncu Yil University Veterinary Faculty Clinic. This research was approved by Van Yuzuncu Yil University Animal Research Ethics Committee (07/03/2019 and Decision no: 2019/02).

Stool samples were taken from calves showing signs of diarrhea or bloody diarrhea. Blood samples were taken from $V$. jugularis to hematological and serum tubes in accordance with the technique for the analysis of hematological and biochemical parameters in Emeria spp. calves with oocyst detected. However, anticoccidial therapy was applied to determine whether diarrhea of blood samples taken from coccidial origin or non-coccidial origin. 20 simmental breeds, which were recorded and responded to anticoccidial therapy, and diarrhea calves with 21-44 days of age and 10 healthy calves were used. The diarrhea of calves that did not respond to anticoccidial therapy was not included in the study considering that diarrhea was caused by mixed infections. Calves with oocyst on microscopic stool examination according to clinical findings and presence of 4000 or above oocysts per gram faeces clinical findings were named as group infected with coccidiosis and healthy calves.

Calves used as subjects were subjected to a general clinical examination and their body temperature, respiratory and pulse numbers were determined. In addition, whether the calves have had any diseases in the past, whether any treatment has been applied or not has been determined by the anamnesis information received from the patient

Examination of stool samples: In the examination of stool samples; in the calves with suspected coccidiosis, $30-50 \mathrm{~g}$ stool sample was taken from the rectum into sterile plastic containers. Fecal samples were examined by native examination method to find Eimeria spp. In the microscopic examination of the feces, blood samples were taken from diarrhea calves with oocyst. The number of oocysts per gram of faeces was determined by the modified McMaster technique. Clinic coccidiosis was confirmed based on presence of 4000 or above oocysts per gram faeces (Chhabra and Pandey 1991; Ocal et al., 2007).

Hematological examinations: For hematological leukocyte $(\mathrm{WBC})$, erythrocyte (RBC), hematocrit (Hct), lymphocyte (Lym), monocyte (Mon), neutrophil (Neu), eosinophil (Eo), basophil (Ba), mean erythrocyte volume (MCV), mean hemoglobin ( $\mathrm{MCH})$, mean erythrocyte hemoglobin concentration (MCHC), hemoglobin $(\mathrm{Hb})$ and platelet $(\mathrm{PLT})$ parameters were measured with a Veterinary Hemogram device.

Biochemical examinations: Serum samples obtained were stored in serum storage tubes at $-20^{\circ} \mathrm{C}$ until biochemical analysis. To determine the serum immunoglobulin (IgA), immunoglobulin (IgE), immunoglobulin (IgG) and immunoglobulin (IgM) concentrations from the serum obtained, measurements were made with the ELISA device using commercial immunoglobulin test kit. Serum total protein (TP), albumin, globulin, urea and creatinine levels of calves with healthy (control) and coccidiosis were measured with the autoanalyzer device. 
Calves with diarrhea and coccidiosis were treated with drugs such as Sulfadimidine sodium $16 \%$, Trimethoprim + sulfadoxine combination as well as anticoccidial treatment, as well as calcium and vitamin $\mathrm{C}$, vitamin $\mathrm{K}$ and epithelial destruction against severe bleeding.

Statistical analysis: Data related to the research results are presented as mean and standard error (Mean \pm SD). In terms of hematological and biochemical parameter analyzes, independent $t$ test (Independent two sample t-test) was used to compare groups with control and coccidiosis. Pearson correlation was used to determine the relationship levels between the variables. $\mathrm{R}$ and SAS statistical software program was used for necessary statistical analysis

\section{Results}

Clinical findings: We have been informed about the anamnesis information of the calves brought to our clinic that the calves are poor, sluggish, stagnant, painful, some have bloody stools and some calves die. As a result of the clinical examination we performed, clinical findings such as calves sluggish, stagnant, mixed hair, abdominal slanted, dehydrated, perineum region and hind limbs were contaminated with feces, increase in tenesmus and heart rate. In addition to the clinical findings detected, images of microscopic examinations of the feces of calves with coccidiosis are given in Figure 1 and Figure 2.

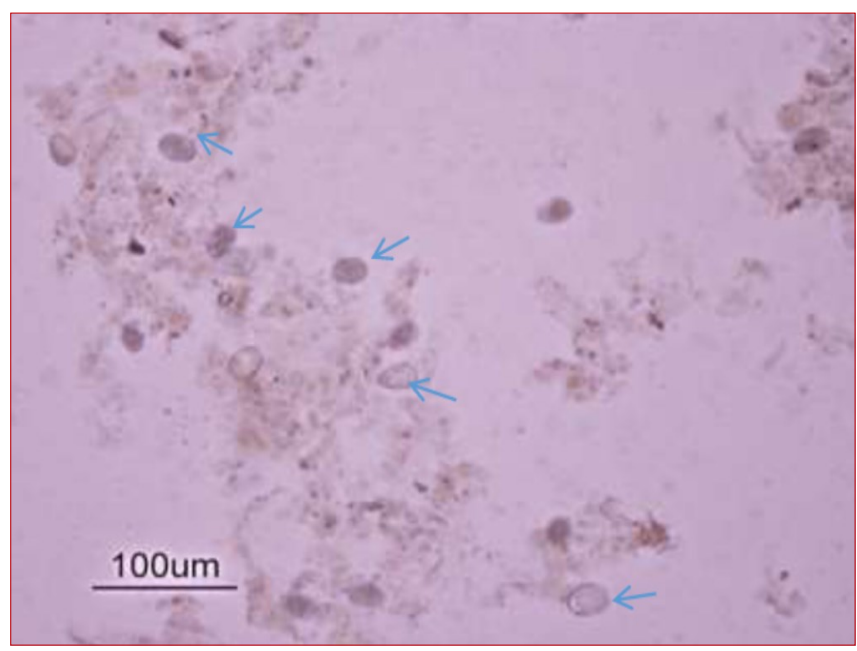

Figure 1. Microscopic image of Eimeria spp oocysts.

Hematological findings: Hematological parameters of coccidiosis and control groups are given in Table 1. In the optional analysis made; WBC, Hct, Mon, Neu (\%) and $M C V$ values of coccidiosis calves were significantly higher than the same parameters of the control group $(\mathrm{P}<0.01, \mathrm{P}<0.05)$, Lymphocyte (Lym) and mean erythrocyte hemoglobin concentration $(\mathrm{MCHC})$ values were found to be significantly low $(P<0.05)($ Table 1$)$.

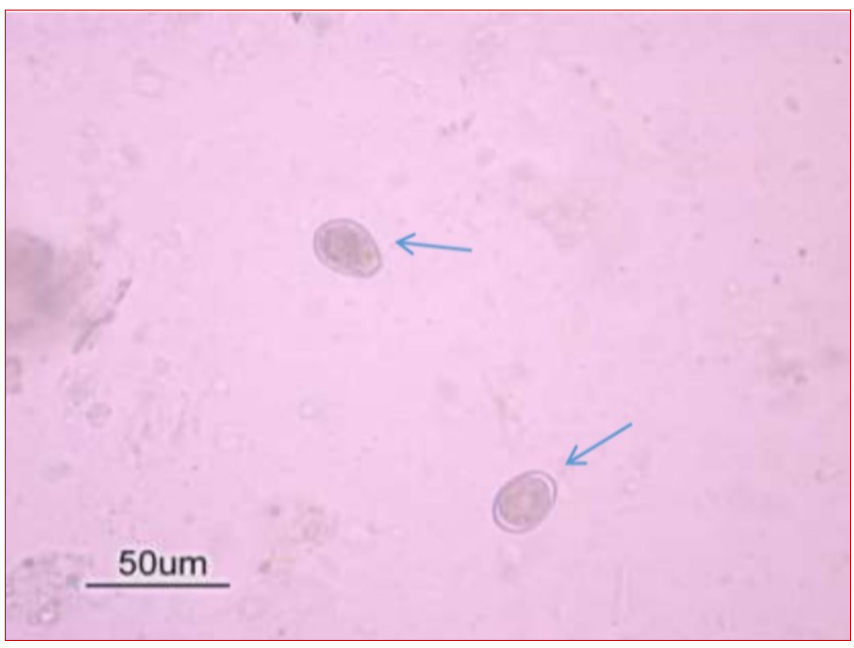

Figure 2. Microscopic image of Eimeria spp oocysts.

Table 1. Hematological parameters in healthy and calves infected with coccidiosis

\begin{tabular}{lcc}
\hline Parameters & $\begin{array}{c}\text { Control group } \\
(\mathrm{n}=10) \\
\overline{\mathrm{x}} \pm \mathrm{SD}\end{array}$ & $\begin{array}{c}\text { Calves infected } \\
\text { with coccidiosis } \\
(\mathrm{n}=20) \\
\overline{\mathrm{x}} \pm \mathrm{SD}\end{array}$ \\
\hline $\mathrm{WBC}\left(10^{3} / \mathrm{mm}^{3}\right)$ & $10.17 \pm 0.81$ & $14.64 \pm 1.31^{*}$ \\
$\mathrm{RBC}\left(10^{6} / \mathrm{mm}^{3}\right)$ & $8.62 \pm 0.28$ & $8.75 \pm 0.44$ \\
Hct $(\%)$ & $23.20 \pm 2.71$ & $28.93 \pm 1.72^{*}$ \\
Lym $\left(10^{3} / \mathrm{mm}^{3}\right)$ & $5.98 \pm 0.49$ & $6.64 \pm 0.91$ \\
Mon $\left(10^{3} / \mathrm{mm}^{3}\right)$ & $0.45 \pm 0.04$ & $0.64 \pm 0.06^{*}$ \\
Neu $\left(10^{3} / \mathrm{mm}^{3}\right)$ & $3.48 \pm 0.37$ & $5.56 \pm 0.39$ \\
Eos $\left(10^{3} / \mathrm{mm}^{3}\right)$ & $0.31 \pm 0.05$ & $0.59 \pm 0.12$ \\
Lym $(\%)$ & $59.17 \pm 2.27$ & $47.39 \pm 3.20^{*}$ \\
Mon $(\%)$ & $4.59 \pm 0.34$ & $4.84 \pm 0.4$ \\
Neu $(\%)$ & $33.99 \pm 2.35$ & $40.42 \pm 3.48^{* *}$ \\
Eos $(\%)$ & $3.15 \pm 0.48$ & $3.26 \pm 0.55$ \\
Bas $(\%)$ & $2.96 \pm 0.58$ & $3.65 \pm 0.57$ \\
MCV (fl) & $26.34 \pm 2.75$ & $31.19 \pm 0.68^{*}$ \\
MCH (pg) & $12.63 \pm 0.38$ & $12.83 \pm 0.28$ \\
MCHC $\left(\mathrm{g} / \mathrm{dl}^{3}\right)$ & $43.36 \pm 0.41$ & $40.42 \pm 1.01^{*}$ \\
Hb $(\mathrm{g} / \mathrm{dl})$ & $10.96 \pm 0.54$ & $11.93 \pm 0.64$ \\
PLT $\left(10^{3} / \mathrm{mm}^{3}\right)$ & $629.10 \pm 85.91$ & $514.90 \pm 68.66$ \\
\hline
\end{tabular}

$\overline{\mathrm{x}} \pm \mathrm{SD}:$ mean \pm standard deviation. ${ }^{*}: \mathrm{P}<0.05,{ }^{*}: \mathrm{P}<0.01$

Biochemical findings: The changes in the biochemical parameters of the coccidiosis and control groups are given in Table 2. As a result of statistical analysis; Urea and creatinine values of calves with coccidiosis were significantly higher than the control group $(p<0.05)$. Although total protein (TP), albumin (Alb) and globulin concentrations of the patient calves were lower than the control group, they were not statistically significant (Table 2). 
Serum immunoglobulin concentrations of coccidiosis and healthy calves are given in Table 3 . In the statistical analysis; IgA, IgE, IgG and IgM values of calves infected with coccidiosis were significantly lower compared to the same parameters of the control group $(P<0.001)$ (Table 3$)$.

Table 2. Biochemical findings in healthy and calves infected with coccidiosis.

\begin{tabular}{lcc}
\hline Parameters & $\begin{array}{c}\text { Control group } \\
(\mathrm{n}=10), \overline{\mathrm{x}} \pm \mathrm{SD}\end{array}$ & $\begin{array}{c}\text { Calves infected with } \\
\text { coccidiosis } \\
(\mathrm{n}=20), \overline{\mathrm{x}} \pm \mathrm{SD}\end{array}$ \\
\hline TP $(\mathrm{g} / \mathrm{dl})$ & $6.13 \pm 0.41$ & $5.54 \pm 0.25$ \\
Albumin (g/dl) & $2.91 \pm 0.12$ & $2.66 \pm 0.11$ \\
Globulin (g/dl) & $3.23 \pm 0.34$ & $2.88 \pm 0.24$ \\
Urea (mg/dl) & $16.84 \pm 2.41$ & $42.82 \pm 8.04^{*}$ \\
Creatinin (mg/dl) & $0.85 \pm 0.09$ & $1.38 \pm 0.17^{*}$ \\
\hline
\end{tabular}

$\overline{\mathrm{x}} \pm \mathrm{SD}:$ mean \pm standard deviation. ${ }^{*}: \mathrm{P}<0.05$

Table 3. Immunoglobulin concentrations in healthy and calves infected with coccidiosis.

\begin{tabular}{lcc}
\hline Parameters & $\begin{array}{c}\text { Control group } \\
(\mathrm{n}=10), \overline{\mathrm{x}} \pm S D\end{array}$ & $\begin{array}{c}\text { Calves infected with } \\
\text { coccidiosis } \\
(\mathrm{n}=20), \overline{\mathrm{x}} \pm \mathrm{SD}\end{array}$ \\
\hline $\lg \mathrm{A}(\mu \mathrm{g} / \mathrm{mL})$ & $2.73 \pm 0.60$ & $0.96 \pm 0.05 * * *$ \\
$\lg E(\mathrm{ng} / \mathrm{mL})$ & $306.68 \pm 24.44$ & $205.62 \pm 3.79 * * *$ \\
$\lg \mathrm{G}(\mu \mathrm{g} / \mathrm{mL})$ & $8.21 \pm 1.27$ & $3.68 \pm 0.17 * * *$ \\
$\lg \mathrm{M}(\mathrm{ng} / \mathrm{mL})$ & $29.98 \pm 2.15$ & $17.37 \pm 0.59 * * *$ \\
\hline
\end{tabular}

$\overline{\mathbf{x}} \pm$ SD $:$ mean \pm standard deviation. ${ }^{* * *}: \mathrm{P}<0.001$.

\section{Discussion}

In studies conducted, it is reported that clinical coccidiosis is more common in animals younger than one year and there is a negative correlation between the rate of infection of cattle and age (Reddy et al., 2015). In another study, although coccidiosis infection occurs at all ages in calves, it is reported that it is more common in calves of 3 weeks and 6 months and that the disease occurs in the first month after birth due to an incubation period of 17 to 21 days (Goz et al., 2006). It was determined that the calves in this study were between the ages of 21-44 days and Eimeria infection was effective in the specified age group. It supports the findings of the researchers ( $G o z$ et al., 2006; Reddy et al., 2015) who stated that the disease is common in young people and causes severe clinical findings.

It has been reported that foul-smelling watery diarrhea, dehydration and obvious anemia are detected in cattle infected with Eimeria bovis (Reddy et al., 2015). In another study, besides fibrin intestinal tissue, abdominal pain, fever, tenesmus, weakness, loss of appetite and weight loss symptoms, clinical coccidiosis is bloody diarrhea (Koutny et al., 2012). The clinical findings obtained in this study are similar to the clinical findings that researchers (Koutny et al., 2012; Reddy et al., 2015) have stated regarding coccidiosis infection.

Many researchers state that WBC numbers are either within normal limits or below normal limits in calf coccidiosis infections (Adams et al., 1992; Knowles et al., 2000). The observed leukopenia is interpreted that the leukocyte curve is caused by the depression phase during acute infection. However, it has been reported that leukocytosis was detected in the study (Willuhn, 1999) related to bovine coccidiosis. In another study (Ghanem and Abd El-Raof, 2005), a significant level of eosinophilia was detected with leukocytosis, and these changes are assumed to be due to intestinal inflammation. In this study, leukocyte values of calves infected with coccidiosis were found higher than healthy calves. WBC values obtained from calves infected with coccidiosis were found to be in agreement with the researchers' reports (Willuhn, 1999; Ghanem and Abd El-Raof, 2005) while there was no significant difference in eosinophil value between calves with coccidiosis and healthy calves. They reported that detected lymphopenia with an increase in neutrophils in buffalo offspring infected with Eimeria spp. (Anwar et al., 1999). It has been shown that Eimeria parasites can be seen as a cellular response to intestinal invasion, as neutrophil increase in the blood and decrease in circulating lymphocytes (Rakhshandehroo et al., 2013). In the current study, it was found that the lymphocyte values of calves infected with coccidiosis showed a statistically significant decrease compared to the calves in the control group. Lymphocyte-related changes in calves with coccidiosis support the data of researchers (Anwar et al., 1999; Rakhshandehroo et al., 2013). In contrast, the neutrophil value of calves with coccidiosis was significantly higher than the control group. It is thought that the increase in neutrophil levels may be related to the cellular response to infections.

It is reported that in cattle with coccidiosis, $\mathrm{Hb}$ concentration is increased and Hct value is low (Knowles et al., 2000; Bangoura and Daugschies, 2007). In another study, it has been reported that Hct value decreases as a result of blood loss or anemia 
that occurs in gastrointestinal system infections of newborn and adult ruminants (Heller and Chiwerge, 2018). It is reported that there are differences in $\mathrm{Hb}$ and Hct values between the calves and control calves (Bangoura and Daugschies, 2007). In this study, the findings we obtained regarding the increase of $\mathrm{Hb}$ value in calves infected with coccidiosis were found to be parallel to the findings of the researchers (Knowles et al., 2000; Bangoura and Daugschies, 2007), but this increase was not found to be statistically significant. Contrary to the findings of the researchers (Knowles et al., 2000; Bangoura and Daugschies, 2007; Heller and Chiwerge, 2018), the Hct values of the calves with coccidiosis were found to be higher $(P<0.05)$ compared to the control group. It is reported that MCV concentration is low (Bangoura and Daugschies, 2007) in experimental Eimeria zuernii infection in calves and MCV concentration is high in the group with severe oocyst. It is assumed that this is due to hemorrhagic diarrhea and high blood and fluid loss, and that immature reticulocytes shift from bone marrow to immature reticulocytes with high cell volume (Martin and Lumsden, 1987; Adams et al., 1992). In this study, MCV value was found to be higher in infected calves whose oocyst presence was found in stool examination compared to the control group and this data was obtained by Adams et al., (1992) and Martin and Lumsden (1987) were found to be in agreement with the findings. Researchers (Anwar et al., 1999) stated that MCHC value was significantly low $(P<0.001)$ in buffalo pups infected with coccidiosis and the decrease could be due to deficiencies of hematopoietic factors. They also stated that a decrease in $\mathrm{MCHC}$ values indicating hyperchromic anemia may be due to low blood loss and low $\mathrm{Hb}$ in erythrocytes. In this study, MCHC values of calves infected with coccidiosis were found lower than the control group $(\mathrm{P}<0.01)$. MCHC values of calves infected with coccidiosis support the researcher's (Anwer et al., 1999). Bangoura et al. (2007) has been reported that the TP and Alb levels of calves infected experimentally with $E$. zuernii oocysts are lower than the control group. It has been reported that serum TP values decrease in the gastrointestinal tract infections of newborn and adult ruminants as a result of blood loss or anemia (Heller and Chiwerge, 2018). In the current study, it was found that the TP and Alb levels of the calves with coccidiosis were lower than the healthy control group. However, decreases in these values were not statistically significant. Decreases in TP and Alb values are similar to the findings of the researchers (Bangoura et al., 2007; Schneider et al.,
2013; Heller and Chiwerge, 2018) although they do not have a significant value. In another study (Bangoura et al., 2007), in experimental research, calves were infected orally with 150,000 sported $E$. zuernii oocytes (moderate infection) and 250,000 sported E. zuernii oocytes (severe infection) per calf, respectively. While TP and Alb concentrations of moderately infected calves were significantly lower than healthy calves $(P<0.05)$, TP and Alb concentrations of severely infected calves were reported to be high. The increase in serum protein levels of severely infected calves reflects increased fluid-related hemoconcentration rather than increased Hct levels and increased availability of serum protein. In general, It is assumed that diarrhea; causes intestinal protein loss and consequently a decreased TP serum concentration (Fitzgerald and Mansfield, 1973; Stockdale et al., 1981). In this study, TP and Alb findings of the calves with coccidiosis were found consistent with the findings of the researchers (Fitzgerald and Mansfield, 1973; Stockdale et al., 1981; Bangoura et al., 2007).

It has been reported that serum Hct values decrease simultaneously as a result of blood loss or anemia occurring in gastrointestinal system infections of newborn and adult ruminants (Heller and Chiwerge, 2018). In our study, although calves with coccidiosis were not considered statistically significant, a decrease in TP was detected. However, Hct value was found to be high at $P<0.05$ in contrast to the findings of the researchers (Knowles et al., 2000; Bangoura and Daugschies, 2007). The reason for this; it is believed that the damage that may cause bleeding in the intestinal mucosa due to the presence of severe dehydration and early infection in calves with diarrhea due to coccidiosis.

In another study (Aydogdu, 2014), there was a positive correlation between TP concentrations and adequate passive transfer, and the serum total protein concentration in newborn calves was $>6 \mathrm{~g} / \mathrm{dl}$, the calf had sufficient passive transfer, and the serum total protein concentration was $<5 \mathrm{~g} / \mathrm{dl}$. It is reported that it can be evaluated as transfer failure. In this study, total protein was found to be $6.13 \pm 0.41 \mathrm{gr} / \mathrm{dl}$ in healthy calves, while the total protein value of calves with coccidiosis was determined as $5.54 \pm 0.25$ $\mathrm{gr} / \mathrm{dl}$. These parameters support the researcher's (Aydogdu, 2014) passive transfer failure and total protein value findings.

Diseases and deaths of newborn calves are important causes of economic loss in the livestock sector (Kozat, 2018). Colostrum is important for the 
growth and health of newborn offspring. Colostrum has a wide antimicrobial effect thanks to the antibody (immunoglobulin) complement system it contains and provides passive immunity to the calf until the immune system matures (Kozat, 2019). There are three different forms of antibodies in the colostrum, namely IgG (IgG1, IgG2), IgA and IgM. 85-90\% of total immunoglobulins are IgG, $5 \% \operatorname{lgA}$ and $7 \% \operatorname{lgM}$ (Kozat, 2019). In addition, IgD and IgE are other Ig types that are less common (Gokce and Erdogan, 2013). Calves in the first 3 to 4 weeks of life can secrete 25 to $30 \%$ of absorbed antibodies in the gastrointestinal tract. However, non-immunized, naturally infected calves have been reported to have low antibody levels against enteropathogens (Al-Alo et al., 2018). The level of passive immune transfer in calves is not only dependent on the immunoglobulin concentration in the colostrum, but the mother's antibody production is also associated with genetics, herd management, nutritional status, and the number of lactations (Kozat, 2018; Kozat, 2019).

It has been reported that calves whose serum Ig concentration exceeding $10 \mathrm{~g} / \mathrm{L}$ in the 30 to 60 hour period of their lives do not become ill before 14 days and the morbidity and disease density is very low (Furman-Fratczak et al., 2011). It confirms the data of many researches that there is a relationship between low serum Ig concentrations of neonatal calves and disease and death events and emphasizes the importance of a passive immune transfer suitable for calf health (Lora et al., 2018; Kozat, 2019). While colostral immunoglobulins provide defense in the

\section{References}

Adams, R., Garry, F. B., Aldridge, B. M., Holland, M. D., \& Odde, K. G. (1992). Haematologic values in newborn beef calves. American Journal of Veterinary Research, 53, 944950.

Al-Alo, K. Z. K., Brujeni, G. N., Lotfollahzadeh, S., Moosakhani, F., \& Gharabaghi, A. (2018). Correlation between neonatal calf diarrhea and the level of maternally derived antibodies. Iranian Journal of Veterinary Research, 19, 3-8.

Anwar, A. H., Kazmi, S. I. H., \& Khan, M. N. (1999). Effects of experimentally induced coccidiosis on some blood parameters of buffalo calves. Pakistan Journal of Biological Sciences, 2, 1024-1026.

Arslan, M. O., Kirmizigul, A. H., Parmaksizoglu, N., \& Erkilic, E. E. (2015). The first case of winter coccidiosis in naturally infected calves with Eimeria zuernii. Atatürk Üniversitesi Veteriner Bilimler Dergisi, 10, 193-197.

Aydın, U. E. \& Aslan, O. (2012). The determination of some treatment and prevention of viral and bacterial infections, growth factors promote intestinal integrity and mucosal healing of diarrhea calves through differentiation of immature and mature cells in the gastrointestinal tract (Chung et al., 2019; Kozat 2019). In the current study, the Ig A, IgE, IgG, Ig M values of the calves infected with coccidiosis were found to be significantly lower compared to the same parameters of the control group $(P<0.01)$ (Table 3$)$. In this study, decreases in immunoglobulin concentrations in calves infected with coccidiosis support data from many investigators (Furman-Fratczak et al., 2011; Al-Alo et al., 2018; Lora et al., 2018; Chung et al., 2019), which reveal relationships between infection and immunoglobulin levels.

As a result, it was revealed that there is a relationship between the risk of infection of calves with coccidiosis and calf immunity. It was concluded that determining the level of passive transfer failure to support neonatal calves to avoid coccidiosis infection and supplementing the calves with deficiency with oral immunoglobulins will reduce the risk of developing coccidial infections.

\section{Conflict of Interest}

In this study, I declare that there are no conflicts of interest among the authors.

\section{Acknowledgements}

This study was financed by Van Yuzuncu Yil University, Scientific Research Projects Coordination Unit and project number TYL-2019-7951.

coagulation parameters at calves cocciodiosis. Veteriner Hekimler Derneği Dergisi, 83, 1-8.

Aydogdu, U. (2014). Sütçü ineklerde kolostrum kompozisyonu ve kalitesinin buzağı pasif immunitesine etkileri. PhD thesis, University of Selçuk, Konya, Turkey .

Bangoura, B., \& Daugschies, A. (2007a). Parasitological and clinical parameters of experimental Eimeria zuernii infection in calves and influence on weight gain and haemogram. Parasitology Research, 100, 1331-1340.

Bangoura, B., Daugschies, A., \& Fuerll, M. (2007b). Influence of experimental Eimeria zuernii infection on clinical blood chemistry in calves. Veterinary Parasitology, 150, 46-53.

Baydar, E., \& Ozubek, S. (2012). A Case of clinical coccidiosis in A Holstein cow. Firat University Veterinary Journal of Health Sciences, 26, 111 -114 . 
Bozdag, A. (2018). The prevalence of Eimeria species in calves and calves in Elazig Karakocan region. PhD thesis, Bingol University, Institute of Science and Technology, Bingöl, Turkey.

Chhabra, R. C., \& Pandey, V. S. (1991). Coccidia of goats in Zimbabwe. Veterinary Parasitology, 39(3-4), 199-205.

Chung, J. J., Rayburn, M. C., \& Chigerwe, M. (2019). Randomized controlled clinical trial on the effect of oral immunoglobulin supplementation on neonatal dairy calves with diarrhea. Journal of Veterinary Internal Medicine, 33, 1807-1813.

Cicek, H., Sevimli, F., Kozan, E., Köse, M., Eser, M., \& Dogan, N. (2007). Prevalence of coccidia in beef cattle in western Turkey. Parasitology Research, 101, 1239-1243.

Fitzgerald, P. R., \& Mansfield, M. E. (1973). Efficacy of monensin against bovine coccidiosis in young Holstein Friesian calves. The Journal of Protozoology, 20, 121-126.

Furman-Fratczak, K., Rzasa, A., \& Stefaniak, T. (2011). The influence of colostral immunoglobulin concentration in heifer calves serum on their health and growth. Journal of Dairy Sciences, 94, 5536-5543.

Ghanem, M. M., \& El-Raof, Y. M. (2005). Clinical and haemato-biochemical studies on lamb coccidiosis and changes following amprolium and sulphadimthoxıne therapy. Benha Veterinary Medical Journal, 286-299.

Gokce, E., \& Erdogan, H. M. (2013). Passive transfer of colostral immunoglobulins in neonatal calves. Turkiye Klinikleri Journal of Veterinary Sciences, 4, 18-46.

Goz, Y., Altug, N., Yuksek, N., \& Ozkan, C. (2006). Parasites detected in neonatal and young calves with diarrhoea. Bulletin of the Veterinary Institute in Pulawy, 50, 345-348.

Heller, M. C., \& Chiwerge, M. (2018). Diagnosis and treatment of infectious enteritis in neonatal and juvenile ruminants.Veterinary Clinics of North America: Food Animal Practice, 34, 101-117.

Knowles, T. G., Edwards, J. E., Bazeley, K. J., Brown, S. N., Butterworth, A., \& Warriss, P. D. (2000). Changes in the blood biochemical and haematological profile of neonatal calves with age. Veterinary Record, 147, 593-598.

Koutny, H., Joachim, A., Tichy, A., \& Baumgartner, W. (2012). Bovine Eimeria species in Austria. Parasitology Research, 110, 1893-1901.

Kozat, S. (2018). Hypothermia in newborn calves. Journal of Istanbul Veterinary Sciences, 2, 30-37.

Kozat, S. (2019). The importance of colostrum management in newborn calves Atatürk University Journal of Veterinary Sciences, 14, 343-353.

Lora, I., Gottardo, F., Contiero, B., Ava, B. D., Bonfanti, L., Stefani, A., \& Baeberio, A. (2018). Association between passive immunity and health status of dairy calves under 30 days of age. Preventive Veterinary Medicine, 152, 1215.
Martin, S. W., \& Lumsden, J.H. (1987). The relationship of hematology and serum chemistry parameters to treatment for respiratory disease and weight gain in Ontario feedlot calves. Preventive Veterinary Medicine, $51,499$.

Mundt, H. C., Bangoura, B., Mengel, H., Keidel, J., \& Daugschies, A. (2005). Control of clinical coccidiosis of calves due to Eimeria bovis and Eimeria zuernii with toltrazuril under field conditions. Parasitology Research, 97, 134-42.

Ocal, N. (2016). Nervöz Koksidiyozis. Turkiye Klinikleri Veterinary Sciences-Internal Medicine-Special Topics, 2(1), 63-67.

Ocal, N., Yagci, B. B., Duru, S. Y., \& Kul, O. (2007). Toltrazuril treatment for acute clinical coccidiosis in hair goat kids: clinical pathological, haematologic and biochemical findings. Medycyna Weterynaryjna, 63(7), 805.

Rakhshandehroo, E., Nazifi, S., Razavi, S. M., Ghane, M., \& Alavi, A. M. (2013). Caprine coccidiosis: the effects of induced infection on certain blood parameters. Veterinarski Arhiv, 83, 623-631.

Reddy, B. S., Sivajothi, S., \& Rayulu, V. C. (2015). Clinical coccidiosis in adult cattle. Journal of parasitic diseases, 39, 557-559.

Schneider, A., Corrêa, M. N., \& Butler, W. R. (2013). Acute phase proteins in Holstein cows diagnosed with uterine infection. Research in Veterinary Science, 95, 269-271.

Şentürk, E., \& Esen, F. (2012). Sepsiste immünoglobulin tedavisi ile kompleman inhibisyonu ve nöroproteksiyon. Türk Anesteziyoloji ve Reanimasyon Dernegi dergisi, 40, 184-192.

Stockdale, P. H., Bainborough, A. R., Bailey, C. B., \& Niilo, L. (1981). Some pathophysiological changes associated with infection of Eimeria zuernii in calves. Canadian Journal of Comparative Medicine and Veterinary Science, 45,34.

Sultana, R., Maqbool, A., Ahmad, M. U. D., Anjum, A. A., Ilyas, S. C., \& Ahmad, M. S. (2014). Control of coccidiosis in calves by vaccination. Journal of Bacteriology and Parasitology, 5,1.

Willuhn, J. (1999). Untersuchungen der butzusammen setzung und charakterisierung peripherer blutlymphozyten im verlauf experimenteller Eimeria bovis infektionen des kalbes. Fachverlag Köhler Giessen, 98.

Yilmaz, N., \& Akgul, Y. (2014). İmmünglobulinler ve septisemi. Uludag University Journal of Faculty of Veterinary Medicine, 33, 33-42. 